\title{
Factors Effecting Mastalgia
}

\author{
Tunc Eren Adem Aslan Ibrahim A. Ozemir Hakan Baysal Julide Sagiroglu Ozgur Ekinci \\ Orhan Alimoglu
}

Department of General Surgery, Istanbul Medeniyet University Goztepe Training and Research Hospital, Istanbul, Turkey

\section{Keywords}

Mastalgia · Etiology · Pain · Surgery

\section{Summary}

Background: Breast pain is one of the leading complaints that ends up with referral to breast surgery clinics. The purpose of the present study was to investigate the factors that cause mastalgia, and its relation with benign or malignant breast disease. Methods: The study was performed in 700 patients. Data obtained from surveys, and imaging findings were prospectively recorded, and analyzed. Results: The mean age was $45.20 \pm 10.78$ years. The mastalgia group included 500 cases; the asymptomatic group comprised 200 individuals. Stressful lifestyle, caffeine consumption, and smoking were associated with mastalgia $(p<0.05)$. Rates of women who had breast fed 3 times or more were higher in the mastalgia group ( $<<0.05$ ). Increased breast density, and breast imaging-reporting and data system (BI-RADS) 2 mammography findings were related with mastalgia ( $p<0.05)$. Cysts and fibroadenomas were more common in the mastalgia group $(p<0.05)$. The incidence of a past history of malignant breast disease was significantly higher in the mastalgia group $(p<0.05)$. Conclusions: Stress, caffeine, smoking, lactation frequency, and benign disorders were factors detected to be related with mastalgia. Although a significant relation between mastalgia and malignant breast disease was detected in our study, more controlled studies are still required to investigate this issue further.

(c) 2016 S. Karger GmbH, Freiburg

\section{Introduction}

Mastalgia is pain arising in the breast tissue. As the most common breast symptom causing women to consult physicians, it may affect up to $70 \%$ of women in their lifetime $[1,2]$. The high level of public awareness about breast cancer and the concern that mastalgia may indicate disease contribute to this trend [3]. It is most common in women aged 30-50 years [4].

Cyclic mastalgia is classically related to the menstrual cycle. It is bilateral, diffuse, poorly localized, and generally described as a heaviness or soreness that often radiates to the axillae and arms $[3,5]$. It occurs most often during the luteal phase as a result of increased water content in breast stroma caused by increasing hormone levels [6]. Cyclic breast pain occurs more often in younger women, mostly resolves spontaneously, and should be separated from premenstrual syndrome [3]. Noncyclic pain is not related to the menstrual cycle, and may be unilateral. It is usually described as a sharp, burning pain that appears to be localized in the breast [7]. Noncyclic mastalgia is most common in women of 40-50 years of age [3].

True breast pain should also be distinguished from chest wall pain, or non-chest wall pain. Chest wall pain may be caused by etiologies such as Tietze's syndrome (costochondritis), radicular pain from cervical arthritis, and localized or diffuse lateral chest wall pain. On the other hand, gallbladder disease, and ischemic heart disease are examples for non-chest wall pain.

Increased estrogen, increased prolactin, decreased progesterone levels, or alterations in the estrogen/progesterone ratio are theories regarding the pathophysiology of mastalgia [8]. Menstrual irregularity, oral contraceptives, hormone therapy, psychotropic drugs, some cardiovascular agents (i.e. spironolactone, digoxin), psychosocial factors, and emotional stress are related with breast pain [3, 9]. Large, pendulous breasts may create ligamentous pain [6]. Caffeine and nicotine consumption are also considered to be related with mastalgia [2].

Cancer is an uncommon cause of breast pain [4]. Breast pain associated with cancer is noncyclic, unilateral, and well localized. Breast cancer is found in $2-7 \%$ of the patients presenting with pain

\section{KARGER \\ Fax +497614520714

Tunc Eren, MD 
as the primary symptom $[1,10-13]$. However, it is not known if mastalgia increases the risk of subsequent breast cancer [4].

Our aim was to investigate the factors in patient history that af fect the incidence of breast pain, and to determine the relationship between mastalgia and benign or malignant breast disease.

\section{Methods}

The study was carried out in the Breast Surgery Unit of the Istanbul Medeniyet University Goztepe Training and Research Hospital, Department of General Surgery, between October 2013 and September 2014. Approval for this study was obtained from the Ethics Committee of the institution, and signed informed consent was obtained from all patients.

The patients were assigned to 1 of 2 groups: the 'mastalgia group', which consisted of patients admitted to our breast surgery unit because of breast pain $(\mathrm{n}=500)$; and the 'asymptomatic group', which comprised patients undergoing routine breast screening $(n=200)$. Patients under any medications other than simple analgesics, such as oral contraceptives, psychotropic agents, hormonal therapy, or cardiovascular agents, as well as patients under 18 , or over 70 years of age were excluded.

All patients enrolled into the study underwent a standard survey concerning their emotional stress level, consumption of caffeine and nicotine, number of infants that they had breast fed, presence of a history of prior bilateral salpingooophorectomy with or without total abdominal hysterectomy, menopausal state, and the presence of any recent direct trauma to the breast. The type of pain, its location, its relationship to the menstrual cycle, and if continuously present, any analgesic drug usage were questioned. Patients having a prior history of treated malignant breast disease were specifically asked if they had experienced mastalgia before the time they received this diagnosis and undergone surgical therapy. All patients underwent a thorough physical examination. The distance between the sternal notch and the nipple was measured, and a length over $33 \mathrm{~cm}$ was considered as macromastia.

Routine radiological breast screening is carried out via mammography for patients older than the age of 40; ultrasonography (US) is carried out when necessary without any restriction for age. In the mammography reports, the intensity patterns are stated as either type A, B, C, or D. Breast density gradually increases from type A to type $\mathrm{D}$, thus, reducing the sensitivity of mammography. In addition, the imaging findings in mammography are classified according to the Breast Imaging-Reporting and Data System (BI-RADS). The BI-RADS categories are defined as: BI-RADS 0, incomplete; BI-RADS 1, normal; BI-RADS 2, benign finding(s); BI-RADS 3, probably benign; BI-RADS 4, suspicious abnormality; BI-RADS 5, highly suggestive of malignancy; and BI-RADS 6, presence of biopsy-proven malignancy.

The mammographic and US findings of our patients were recorded. For the patients referred to biopsy or surgical treatment, the results of the pathological evaluations were followed-up and recorded. The NCSS (Number Cruncher Statistical System) 2007, and PASS (Power Analysis and Sample Size) 2008 Statistical Software (Utah, USA) programs were used for statistical analysis. In addition to the descriptive statistical methods (mean, standard deviation, frequency, ratio), the Student's $t$-test was used to compare numerical quantities of parameters with normal distribution. The Mann-Whitney $U$ test was used for the comparison of 2 groups with any maldistribution of parameters. Fisher's exact test, Pearson's chi-squared test, and Yates' continuity correction were used for the qualitative comparisons of the data. Differences were considered statistically significant when $\mathrm{p}<0.05$.

\section{Results}

A total of 700 women with a mean age of $45.20 \pm 10.78$ years (range 18-67) were enrolled. The 'mastalgia group' comprised 500 patients and the 'asymptomatic group' 200 patients. Mean age was significantly higher in the mastalgia group $(\mathrm{p}=0.001)$ (table 1$)$.

The number of patients who declared increased emotional stress level was significantly higher in the mastalgia group $(\mathrm{p}<0.01)$. Caffeine intake, and smoking were significantly related with mastalgia $(\mathrm{p}<0.05)$. Lactation frequency (number of breastfed infants) revealed significantly higher rates in the mastalgia group $(\mathrm{p}<0.05)$. The number of patients with a surgical history of prior bilateral salpingo-oophorectomy with or without total abdominal hysterectomy was significantly higher in the asymptomatic group $(\mathrm{p}<0.01)$. Postmenopausal state, and macromastia were related with decreased incidences of mastalgia $(\mathrm{p}<0.01)$. The presence of a recent history of direct trauma to the breast tissue did not reveal any statistical significance between the two groups $(p>0.05)$. When questioned for a history of previously treated malignant breast disease, a significant relation between mastalgia and malignancy was determined ( $\mathrm{p}<0.05$ ). The comparisons of the factors in patient history between the mastalgia group and the asymptomatic group are summarized in table 1.

The rates of the type, location, and laterality of breast pain in the mastalgia group are summarized in table 2 . In the mastalgia group, the number of patients on continuous consumption of metamizole, non-steroid anti-inflammatory drugs (NSAIDs), and paracetamol were significantly higher $(\mathrm{p}<0.05)$ (table 3 ).

Mammographic screening was carried out on 377 patients in the mastalgia group, and 126 patients in the asymptomatic group. A type A breast density pattern was more frequent in the asymptomatic group, and type B more common in the mastalgia group ( $\mathrm{p}<0.01)$. According to the BI-RADS categories, BI-RADS 1 was more frequent in the asymptomatic group, and BI-RADS 2 in the mastalgia group $(p<0.01)$. When US images were evaluated, the incidences of simple cysts and fibroadenomas were higher in the mastalgia group $(\mathrm{p}<0.05)$. The comparison of the radiological findings between the two groups is shown in table 4 .

All of the 8 patients diagnosed with BI-RADS 4 were in the mastalgia group. According to their biopsy results, 6 of these patients had malignant disease, leading to surgical intervention. Postoperative pathological evaluations revealed ductal carcinoma in situ (DCIS) in 1 patient, invasive mucinous carcinoma in 2 , and invasive ductal carcinoma in 3 patients. Additionally, 6 patients were diagnosed with BI-RADS 5, and were referred to surgery. 5 of these patients were in the mastalgia group, and 1 in the asymptomatic group. Postoperative pathological evaluations revealed DCIS in 1, and invasive mucinous carcinoma in another patient, while invasive ductal carcinoma was detected in 4 patients.

In the mastalgia group, the patients were divided into two subgroups according to the radiation of breast pain as 'diffuse breast pain' or 'localized breast pain'. When US findings for these subgroups were evaluated, the incidence of fibrocystic disease was higher in the 'diffuse breast pain' group with a rate of $90.9 \%$ $(\mathrm{p}<0.01)$ (table 5). 
Table 1. Comparison of factors in patient history between the mastalgia and asymptomatic groups

\begin{tabular}{|c|c|c|c|c|c|}
\hline & & Total & Mastalgia & Asymptomatic & $\mathrm{p}$ \\
\hline Age mean $\pm S D$, years & & $45.20 \pm 10.78$ & $46.19 \pm 10.51$ & $42.73 \pm 11.06$ & ${ }^{\mathrm{a}} 0.001^{* *}$ \\
\hline Patients, $\mathrm{n}$ & & 700 & 500 & 200 & \\
\hline \multirow[t]{2}{*}{ Stress, n (\%) } & none & $152(21.7)$ & $84(16.8)$ & $68(34.0)$ & ${ }^{\mathrm{b}} 0.001^{* *}$ \\
\hline & stressful & $548(78.3)$ & $416(83.2)$ & $132(66.0)$ & \\
\hline \multirow[t]{3}{*}{ Caffeine consumption (coffee), $\mathrm{n}(\%)$} & none & $457(65.3)$ & $310(62.0)$ & $147(73.5)$ & ${ }^{\mathrm{b}} 0.004^{* *}$ \\
\hline & 1 cup/day & $112(16.0)$ & $90(18.0)$ & $22(11.0)$ & $\mathrm{b}_{0} 0.022^{*}$ \\
\hline & $\geq 2$ cups/day & $131(18.7)$ & $100(20.0)$ & $31(15.5)$ & b0.168 \\
\hline \multirow[t]{3}{*}{ Smoking (cigarettes), n (\%) } & none & $474(67.7)$ & $322(64.4)$ & $152(76.0)$ & b $0.003^{* *}$ \\
\hline & $5-10 /$ day & $128(18.3)$ & $97(19.4)$ & $31(15.5)$ & b0.228 \\
\hline & $>10 /$ day & $98(14.0)$ & $81(16.2)$ & $17(8.5)$ & $\mathrm{b}_{0} 0008^{* *}$ \\
\hline \multirow[t]{5}{*}{ Lactation (breast-fed infants), n (\%) } & 0 & $72(10.3)$ & $24(4.8)$ & $48(24.0)$ & b $0.001^{* *}$ \\
\hline & 1 & $91(13.0)$ & $54(10.8)$ & $37(18.5)$ & ${ }^{\mathrm{b}} 0.006^{* *}$ \\
\hline & 2 & $223(31.9)$ & $162(32.4)$ & $61(30.5)$ & b0.569 \\
\hline & 3 & $187(26.7)$ & $160(32.0)$ & $27(13.5)$ & ${ }^{\mathrm{b}} 0.001^{* *}$ \\
\hline & $\geq 4$ & $127(18.1)$ & $100(20.0)$ & $27(13.5)$ & $\mathrm{b}_{0} 0.044^{*}$ \\
\hline \multirow[t]{2}{*}{$\mathrm{BSO} \pm \mathrm{TAH}, \mathrm{n}(\%)$} & no & $674(96.3)$ & $492(98.4)$ & $182(91.0)$ & ${ }^{c} 0.001^{* *}$ \\
\hline & yes & $26(3.7)$ & $8(1.6)$ & $18(9.0)$ & \\
\hline \multirow[t]{2}{*}{ Menopause, n (\%) } & premenopausal & $534(76.3)$ & $412(82.4)$ & $122(61.0)$ & b $0.001^{* *}$ \\
\hline & postmenopausal & $166(23.7)$ & $88(17.6)$ & $78(39.0)$ & \\
\hline \multirow[t]{2}{*}{ Breast size, n (\%) } & normal & $664(94.9)$ & $484(96.8)$ & $180(90.0)$ & ${ }^{c} 0.001^{* *}$ \\
\hline & macromastia & $36(5.1)$ & $16(3.2)$ & $20(10.0)$ & \\
\hline \multirow[t]{2}{*}{ Recent breast trauma, n (\%) } & no & $691(98.7)$ & $491(98.2)$ & $200(100.0)$ & d 0.067 \\
\hline & yes & $9(1.3)$ & $9(1.8)$ & $0(0.0)$ & \\
\hline \multirow[t]{2}{*}{ Breast cancer, n (\%) } & no & $666(95.1)$ & $469(93.8)$ & $197(98.5)$ & ${ }^{c} 0.016^{*}$ \\
\hline & yes & $34(4.9)$ & $31(61.2)$ & $3(1.5)$ & \\
\hline
\end{tabular}

aStudent's t-test

'Pearson's chi-squared test

'Yates' continuity correction

${ }^{\mathrm{d}}$ Fisher's exact test

${ }^{*} \mathrm{p}<0.05,{ }^{* *} \mathrm{p}<0.01$

$\mathrm{SD}=$ standard deviation, $\mathrm{BSO} \pm \mathrm{TAH}$ : history of a prior bilateral salpingo-oophorectomy with or without total abdominal hysterectomy.

Table 2. Distribution of the patients in the mastalgia group according to their types of pain

\begin{tabular}{llrl}
\hline Breast pain & & $\mathrm{n}$ & $\%$ \\
\hline Radiation & diffuse & 237 & 47.4 \\
& localized & 263 & 52.6 \\
Laterality & bilateral & 89 & 17.8 \\
& unilateral & 411 & 82.2 \\
Relation with menstruation & cyclic & 367 & 73.4 \\
& noncyclic & 133 & 26.6
\end{tabular}

\section{Discussion}

There may be many factors effecting mastalgia. In a series of 1,219 patients, Johnson et al. [14] reported that the age of women complaining of breast pain was between 35 and 55 years, and that this symptom was rarely encountered under the age of 45 . In the present study, the mean age of the total study group was $45.20 \pm 10.78$ years (range 18-67), and the mean age of the mastalgia group was higher revealing that breast pain often takes place in
Table 3. Comparison of analgesic consumption between the mastalgia and asymptomatic groups

\begin{tabular}{|c|c|c|c|c|}
\hline & Total & Mastalgia & Asymptomatic & $\mathrm{p}$ \\
\hline \multicolumn{5}{|c|}{ Analgesic consumption, n (\%) } \\
\hline None & $552(78.9)$ & $357(71.4)$ & $195(97.5)$ & ${ }^{\mathrm{a}} 0.001^{* *}$ \\
\hline ASA & $8(1.1)$ & $8(1.6)$ & $0(0.0)$ & ${ }^{\mathrm{b}} 0.113$ \\
\hline Metamizole & $17(2.4)$ & $17(3.4)$ & $0(0.0)$ & ${ }^{\mathrm{b}} 0.005^{* *}$ \\
\hline NSAIDs & $120(17.1)$ & $118(23.6)$ & $2(1.0)$ & ${ }^{\mathrm{a}} 0.001^{* *}$ \\
\hline Paracetamol & $3(0.4)$ & $0(0.0)$ & $3(1.5)$ & ${ }^{\mathrm{b}} 0.023^{*}$ \\
\hline
\end{tabular}

'Yates' continuity correction

${ }^{b}$ Fisher's exact test

${ }^{*} \mathrm{p}<0.05,{ }^{* *} \mathrm{p}<0.01$

ASA $=$ acetylsalycilic acid, NSAIDs $=$ non-steroid anti-inflammatory drugs.

the perimenopausal period when hormonal and menstrual irregularity takes place $(\mathrm{p}<0.01)$.

There are numerous studies demonstrating a relationship between mastalgia and psychological stress [15-17]. Ader et al. [2] showed a relationship between increased stress and mastalgia, and Preece et al. [15] reported that mastalgia was a manifestation of psychoneurosis. In our study, the number of patients describing 
Table 4. Comparison of mammography and ultrasound findings between the mastalgia and asymptomatic groups

\begin{tabular}{|c|c|c|c|c|}
\hline & Total, n (\%) & $\begin{array}{l}\text { Mastalgia, } \mathrm{n} \\
(\%)\end{array}$ & $\begin{array}{l}\text { Asymptomatic, } \mathrm{n} \\
(\%)\end{array}$ & $\mathrm{p}$ \\
\hline \multicolumn{5}{|c|}{ Mammographic breast density (pattern) $(\mathrm{n}=503)$} \\
\hline A & $44(8.7)$ & $21(5.6)$ & $23(18.3)$ & ${ }^{\mathrm{a}} 0.001^{* *}$ \\
\hline B & $373(74.2)$ & $299(79.3)$ & $74(58.7)$ & ${ }^{\mathrm{a}} 0.001^{\star *}$ \\
\hline $\mathrm{C}$ & $80(15.9)$ & $54(14.3)$ & $26(20.6)$ & ${ }^{\mathrm{a}} 0.094$ \\
\hline $\mathrm{D}$ & $6(1.2)$ & $3(0.8)$ & $3(2.4)$ & b 0.169 \\
\hline \multicolumn{5}{|c|}{ Mammographic BI-RADS category $(\mathrm{n}=503)$} \\
\hline BI-RADS 0 & $278(55.3)$ & $210(55.7)$ & $68(54.0)$ & a 0.735 \\
\hline BI-RADS 1 & $62(12.3)$ & $29(7.7)$ & $33(26.2)$ & ${ }^{\mathrm{a}} 0.001^{\star *}$ \\
\hline BI-RADS 2 & $127(25.2)$ & $110(29.2)$ & $17(13.5)$ & ${ }^{\mathrm{c}} 0.001^{* *}$ \\
\hline BI-RADS 3 & $22(4.4)$ & $15(4.0)$ & $7(5.6)$ & ${ }^{\mathrm{c}} 0.619$ \\
\hline BI-RADS 4 & $8(1.6)$ & $8(2.1)$ & $0(0.0)$ & $\mathrm{b}_{0} 0.210$ \\
\hline BI-RADS 5 & $6(1.2)$ & $5(1.3)$ & $1(0.8)$ & $\mathrm{b}^{\mathrm{b}} 1.000$ \\
\hline \multicolumn{5}{|c|}{ Ultrasound findings $\dagger(n=513)$} \\
\hline Normal & $80(15.6)$ & $59(16.6)$ & $21(13.4)$ & ${ }^{\mathrm{a}} 0.358$ \\
\hline Simple cyst(s) & $30(5.8)$ & $30(8.4)$ & $0(0.0)$ & ${ }^{c} 0.001^{* *}$ \\
\hline Fibroadenoma(s) & $68(13.3)$ & $55(15.4)$ & $13(8.3)$ & ${ }^{c} 0.039^{*}$ \\
\hline Fibrocystic disease & $323(63.0)$ & $297(83.4)$ & $123(78.3)$ & b 0.168 \\
\hline IMLN & $8(1.6)$ & $8(2.2)$ & $0(0.0)$ & b 0.114 \\
\hline Complex cyst(s) & $2(0.4)$ & $2(0.6)$ & $0(0.0)$ & ${ }^{b} 1.000$ \\
\hline Fatty tissue necrosis & $2(0.4)$ & $2(0.6)$ & $0(0.0)$ & ${ }^{b} 1.000$ \\
\hline $\begin{array}{l}\text { 'Pearson's chi-squared tes } \\
\text { ' }{ }^{\mathrm{b}} \text { Fisher's exact test } \\
\text { 'Yates' continuity correct } \\
{ }^{*} \mathrm{p}<0.05,{ }^{* *} \mathrm{p}<0.01 \\
\dagger \text { †Some cases harbor mult } \\
\text { IMLN = intramammary }\end{array}$ & nd findings & & & \\
\hline
\end{tabular}

themselves as having a 'stressful lifestyle' was significantly higher in the mastalgia group $(\mathrm{p}<0.01)$.

The relationship of caffeine consumption and smoking with breast pain is controversial $[4,8]$. In their series of 874 cases, Ader et al. [2] reported that increased caffeine consumption and smoking were correlated with mastalgia. In the present study, there was significant relationship between either regular caffeine consumption or heavy smoking (> 10 cigarettes/day) and breast pain $(\mathrm{p}<0.05)$.

It has been shown that increased estrogen levels, decreased progesterone levels, irregularities of the estrogen/progesterone ratio, or increased prolactin levels are associated with mastalgia $[18,19]$. The cyclic nature of the breast pain, the presence of breast symptoms such as swelling, tenderness, and nodularity, and the cessation of these symptoms in the postmenopausal period are probably due to the effects of the estrogen hormone [20, 21]. Considering lactation, the percentage of women with a history of breast feeding 3 or more infants was increased in the mastalgia group $(\mathrm{p}<0.01)$. These results highlight the correlation of mastalgia with the increased incidences of lactation, which is associated with increased number of births, and thus with increased exposure to the effects of high estrogen and prolactin levels. Additionally, 3 or more periods of lactation may result with anatomical changes in the breast tissue, especially in the ductal system, such as ductal ectasia, which may also lead to mastalgia.

In their study of 1,219 patients, Johnson et al. [14] found that the majority of their asymptomatic patients were postmenopausal.
Table 5. Comparison of the ultrasound findings according to the radiation of pain in the mastalgia group

\begin{tabular}{lccc}
\hline & \multicolumn{2}{l}{ Radiation of breast pain, $\mathrm{n}(\%)$} & \multirow{2}{*}{$\mathrm{p}$} \\
\cline { 2 - 3 } & \multicolumn{2}{c}{ Diffuse } & Localized \\
\hline Ultrasound findings $\dagger$ & & & \\
$\quad$ Normal & $24(13.7)$ & $35(19.3)$ & ${ }^{\mathrm{a}} 0.154$ \\
Simple cyst(s) & $12(6.9)$ & $18(9.9)$ & ${ }^{\mathrm{b}} 0.391$ \\
Fibroadenoma(s) & $25(14.3)$ & $30(16.6)$ & ${ }^{\mathrm{a}} 0.550$ \\
Fibrocystic disease & $159(90.9)$ & $138(76.2)$ & ${ }^{\mathrm{a}} 0.001^{* *}$ \\
IMLN & $4(2.3)$ & $4(2.2)$ & ${ }^{\mathrm{c}} 1.000$ \\
Complex cyst(s) & $2(1.1)$ & $0(0.0)$ & ${ }^{\mathrm{c}} 0.241$ \\
Fatty tissue necrosis & $0(0.0)$ & $2(1.1)$ & ${ }^{\mathrm{c}} 0.499$ \\
\hline
\end{tabular}

a'Pearson's chi-squared test

'Yates' continuity correction

'Fisher's exact test

${ }^{*} \mathrm{p}<0.05,{ }^{* *} \mathrm{p}<0.01$

$\dagger$ Some cases harbor multiple ultrasound findings

IMLN = intramammary lymph node(s).

Other studies have also reported a significant relationship between the asymptomatic group and postmenopausal state [22, 23]. In our study, the proportion of postmenopausal women in the asymptomatic group was significantly higher, indicating that decreased estrogen levels may lead to diminished breast pain symptoms $(\mathrm{p}<0.01)$. A surgical history of a prior bilateral salpingo-oopho- 
rectomy with or without total abdominal hysterectomy was associated with a significantly decreased incidence of breast pain, again supporting this notion $(\mathrm{p}<0.01)$.

Hernanz et al. [24] described a distance between the sternal notch and the nipple of more than $33 \mathrm{~cm}$ as being a criterion of macromastia. Macromastia can lead to severe pain in the back and shoulders, as well as intertrigo, problems with body image perception, impairments with quality of life, and limitations in physical functioning $[25,26]$. However, in these studies parenchymal pain, which is referred to as 'true breast pain', was not investigated. During the examinations of our patients, symptoms such as back pain or shoulder pain were not considered, and only symptoms of true parenchymal breast pain were recorded. In the present study, the incidence of macromastia was significantly lower in the mastalgia group $(\mathrm{p}<0.01)$, suggesting that macromastia might not be one of the factors that cause mastalgia.

Mastalgia may occur due to fatty tissue necrosis, or a strain in the Cooper ligaments as results of either blunt or penetrating trauma to the breast [27]. In our study, although the presence of a recent history of direct trauma to the breast showed no significant difference between the groups, higher rates of trauma history in the mastalgia group was remarkable ( $p>0.05)$.

Roughly 2 thirds of breast pain is cyclic and 1 third noncyclic [4]. In a study including 1,150 patients that investigated the causes of mastalgia, the rates of cyclic and noncyclic mastalgia were found to be $61.5 \%$ and $38.5 \%$, respectively [28]. In the mastalgia group of the present study, the rates of cyclic and noncyclic mastalgia were $73.4 \%$, and $26.6 \%$, respectively, while $47.4 \%$ of the patients suffered from diffuse pain, and $52.6 \%$ from localized pain.

Persistent severe mastalgia can occur in $10-22 \%$ of patients, and requires medical treatments such as tamoxifen, danazol, bromocriptine, or the application of evening primrose oil, etc. [6, 29] Generally, these types of therapies are not preferred in breast surgery clinics. As a first-step approach, agents such as acetaminophen, NSAIDs, and topical diclofenac are preferred, which are easier to obtain with better patient compliance, and are often effective $[7,30]$. In the present study, the ratio of regular analgesic use between the groups was observed to be higher in the mastalgia group, and the most preferred analgesic type was NSAIDs $(\mathrm{p}<0.01)$.

An association between mastalgia and increased breast density has been reported $[18,31,32]$. In our study, a type B breast pattern was more common in the mastalgia group $(\mathrm{p}<0.01)$. There were no significant differences in terms of the incidences of type $\mathrm{C}$, or type $\mathrm{D}$ patterns between the 2 groups $(\mathrm{p}>0.05)$. These results show that, although increased mammographic intensity is associated with mastalgia, no significant difference occurs when breast density exceeds a certain value.

Benign breast disorders are significantly associated with mastalgia $[28,33,34]$. On the other hand, although some publications demonstrate a relationship of mastalgia with breast cancer, this issue is still controversial $[4,23,35,36]$. Our series showed a higher frequency of mastalgia in patients with findings of benign breast disorders (BI-RADS 2) $(\mathrm{p}<0.01)$. Some studies indicate a ratio of $2-7 \%$ for the presence of a malignancy in patients with mastalgia $[1,10-13]$. Among the patients with BI-RADS 4 and BI-RADS 5 findings in our series, 13 were in the mastalgia group, and 1 in the asymptomatic group, suggesting the existence of a mild relationship of mastalgia with higher BI-RADS categories, albeit not reaching statistical significance.

The relationship between breast pain and benign lesions detected using US is also controversial [23,34]. In their series of 1,150 mastalgia patients, Kizilkaya et al. [28] reported that fibroadenomas and simple cysts were the most common coexisting benign lesions. In our series, the rates of simple cysts and fibroadenomas seen using US were higher in the mastalgia group $(\mathrm{p}<0.05)$. Additionally, the incidence of fibrocystic disease detected by US was significantly higher in patients with diffuse breast pain $(\mathrm{p}<0.05)$. Since fibrocystic disease is an entity showing a generalized involvement of the breast parenchyma, that it leads to diffuse breast pain is not unexpected.

Despite the high probability of the coexistence of a malignant breast tumor with noncyclic breast pain, it should always be kept in mind that, although rare, cyclical mastalgia can also be associated with malignancy $[1,10-13,28]$. In two controlled studies and a cohort study, the risk of breast cancer has been shown to increase significantly in women with cyclical mastalgia $[23,35,36]$. On the other hand, contrasting results have been published [37]. In the present study, the incidence of a previous history of breast cancer was significantly higher in the mastalgia group $(\mathrm{p}<0.05)$. This group included patients who were not newly diagnosed, but had been surgically treated due to breast cancer, and were continuing their screening programs. Therefore, all of these patients were specifically questioned about the onset of mastalgia, and it was confirmed that the mastalgia was present before the identification of malignancy. Although the results of our study reflect an association between mastalgia and malignancy, this issue is still controversial, and there is still need for large prospective studies to reveal the relationship more precisely.

\section{Acknowledgements}

Each author acknowledges that the final manuscript has been prepared and submitted with his/her approval. The authors would like to thank Mrs. Emire Bor (EMPIAR Statistics, Istanbul, Turkey) for the statistical work-up of this study.

\section{Disclosure Statement}

All authors declare that no conflict of interest exists, and that they have no direct or indirect commercial financial incentive associated with publishing this article. The authors also confirm that this manuscript has not been previously published, and is not under simultaneous consideration by another journal or electronic publication. All authors have read and complied with the requirements set forth in the Instructions to Authors. 


\section{References}

1 Preece PE, Baum M, Mansel RE, et al.: Importance of mastalgia in operable breast cancer. Br Med J (Clin Res Ed) 1982;284:1299-1300.

$\checkmark 2$ Ader DN, South-Paul J, Adera T, et al.: Cyclical mastalgia: Prevalence and associated health and behavioral factors. J Psychosom Obstet Gynaecol 2001;22:71-76.

3 Morrow M: The evaluation of common breast prob lems. Am Fam Physician 2000;61:2371-2378.

4 Goyal A, Mansel RE: Mastalgia; in Jatoi I, Kaufmann $M$ (eds): Management of breast disease. Springer-Verlag, Berlin, 2010, pp. 69-76.

5 Schorge J: Breast disease; in Schorge J, Schaffer J, Halvorson L, et al. (eds): Williams Gynecology, 1st ed. McGraw-Hill Medical, New York, NY, 2008, pp. 269290.

6 Smith RL, Pruthi S, Fitzpatrick LA: Evaluation and management of breast pain. Mayo Clin Proc 2004;79: 353-372.

7 Salzman B, Fleegle S, Tully AS: Common breast problems. Am Fam Physician 2012;86:343-349.

8 Iddon J: Mastalgia; in Dixon JM (ed): ABC of breast disease, 3rd ed. Blackwell Publishing, Edinburgh, UK, 2006, pp. 15-18.

9 Leung JW, Korguth PJ, Gotway MB: Utility of targeted sonography in the evaluation of focal breast pain. J Ultrasound Med 2002;21:521-526.

10 Barton MB, Elmore JG, Fletcher SW: Breast symptoms among women enrolled in a health maintenance organization: frequency, evaluation, and outcome. Ann Intern Med 1999;130:651-657.

11 Lumachi F, Ermani M, Brandes AA, et al.: Breast complaints and risk of breast cancer. Population-based study of 2879 self-selected women and long-term follow-up. Biomed Pharmacother 2002;56:88-92.

12 Fariselli G, Lepera P, Viganotti G, et al.: Localized mastalgia as presenting symptom in breast cancer. Eur Surg Oncol 1988;14:213-215.

13 Smallwood JA, Kye DA, Taylor I: Mastalgia; is this commonly associated with operable breast cancer? Ann R Coll Surg Engl 1986;68:262-263.
14 Johnson KM, Bradley KA, Bush K, et al.: Frequency of mastalgia among women veterans. Association with psychiatric conditions and unexplained pain syndromes. J Gen Intern Med 2006;21(Suppl 3):S70-75.

15 Preece PE, Mansel RE, Hughes LE: Mastalgia: Psychoneurosis or organic disease? Br Med J 1978;1:29-30.

16 Jenkins PL, Januil N, Gateley C, et al.: Psychiatric illness in patients with severe treatment-resistant mastalgia. Gen Hosp Psychiatry 1993;15:55-57.

17 Colegrave S, Holcombe C, Salmon P: Psychological characteristics of women presenting with breast pain. J Psychosom Res 2001;50:303-307.

18 Tejwani PL, Srivastava A, Nerkar H, et al.: Centchroman regresses mastalgia: A randomized comparison with danazol. Indian J Surg 2011;73:199-205.

19 Rose DP, Boyar AP, Cohen C, et al.: Effect of a low-fat diet on hormone levels in women with cystic breast disease. I. Serum steroids and gonadotropins. J Natl Cancer Inst 1987;78:623-626.

20 Wang DY, Fentiman IS: Epidemiology and endocrinology of benign breast disease. Breast Cancer Res Treat 1985;6:5-36.

21 Wisbey JR, Kumar S, Mansel RE, et al.: Natural history of breast pain. Lancet 1983;2:672-674.

22 Tavaf-Motamen H, Ader DN, Browne MW, et al.: Clinical evaluation of mastalgia. Arch Surg 1998;133: 211-214.

23 Plu-Bureau G, Le MG, Sitruk-Ware R, et al.: Cyclical mastalgia and breast cancer risk: Results of a French cohort study. Cancer Epidemiol Biomarkers Prev 2006; 15:1229-1231.

24 Hernanz F, Santos R, Arruabarrena A, et al.: Treatment of symptomatic macromastia in a breast unit. World J Surg Oncol 2010;8:93.

25 Degeorge BR Jr, Colen DL, Mericli AF, et al.: Reduction mammoplasty operative techniques for improved outcomes in the treatment of gigantomastia. Eplasty 2013;13:e54.
6 Salgado CJ, Mardini S, Chen HC: Mastodynia refractory to medical therapy: Is there a role for mastectomy and breast reconstruction? Plast Reconstr Surg 2005; 116:978-985.

27 Santen RJ, Mansel R: Benign breast disorders. N Engl J Med 2005;353:275-285.

28 Kizilkaya MC, Erozgen F, Kocakusak A, et al.: Mastalgia in daily practice. J Breast Health 2013;9:191-194.

29 Srivastava A, Mansel RE, Arvind N, et al.: Evidencebased management of mastalgia: A meta-analysis of randomised trials. Breast 2007;16:503-512.

30 Colak T, Ipek T, Kanik A, et al.: Efficacy of topical nonsteroidal antiinflammatory drugs in mastalgia treatment. J Am Coll Surg 2003;196:525-530.

31 Kumar S, Rai R, Agarwal GG, et al.: A randomized, double-blind, placebo-controlled trial of ormeloxifene in breast pain and nodularity. Natl Med J India 2013; 26:69-74.

32 Christodoulakos GE, Lambrinoudaki IV, Vourtsi AD, et al.: Breast pain and mammographic density increase as a consequence of raloxifene therapy. J Endocrinol Invest 2002;25:564-566.

33 Khanna AK, Tapodar J, Misra MK: Spectrum of benign breast disorders in a university hospital. J Indian Med Assoc 1997;95:5-8.

34 Yuksekkaya R, Celikyay F, Voyvoda N, et al.: Breast ultrasound findings in patients with mastalgia under the age of fourty. J Breast Health 2012;8:19-22.

35 Goodwin PJ, DeBoer G, Clark RM, et al.: Cyclical mastopathy and premenopausal breast cancer risk. Results of a case-control study. Breast Cancer Res Treat 1995; 33:63-73.

36 Plu-Bureau TJC, Sitruk-Ware R, Asselain B, et al.: Cyclical mastalgia as a marker of breast cancer susceptibility: Results of a case-control study among French women. Br J Cancer 1992;65:945-949.

37 Khan SA, Apkarian AV: Mastalgia and breast cancer: A protective association? Cancer Detect Prev 2002;26: 192-196. 